Vol. 1, No. 2, Desember, 2016, ISSN 2527 - 2853

\title{
Desain Interior Unit Transfusi Darah (UTD) PMI Surabaya dengan Konsep Modern Youth
}

\author{
Intan Hannah Marysa ${ }^{1}$, Nanik Rachmaniyah ${ }^{2}$ \\ 1,2 Jurusan Desain Interior, FTSP, Institut Teknologi Sepuluh Nopember, Surabaya, Indonesia \\ intanhannahmarysa@gmail.com ${ }^{1}$, rachmaniyah@gmail.com²
}

\begin{abstract}
ABSTRAK
Pemuda merupakan populasi terbesar di Indonesia dan menjadi harapan untuk meningkatkan jumlah ketersediaan darah di Indonesia. PMI membuat program "Yang Muda Yang Berdonor" mengajak pemuda untuk menjadikan donor darah sebagai gaya hidup. Selain program tersebut perlu adanya strategi untuk menarik pemuda datang mendonorkan darahnya ke Unit Transfusi Darah (UTD) PMI Surabaya. Improvisasi pada kondisi dan fasilitas UTD PMI Surabaya melalui desain interior merupakan salah satu strategi yang dapat dilakukan untuk mendukung peningkatan pendonor darah dari kalangan usia muda. Dalam menentukan konsep dan desain interior UTD PMI Surabaya digunakan metode desain melalui tahap pengumpulan data (observasi, wawancara, survey, studi literatur) dan tahapan desain (eksplorasi ide konsep, sketsa-sketsa, dan implementasi desain). Melalui proses tersebut didapatkan konsep yaitu Modern Youth. Konsep Modern Youth merupakan konsep yang disesuaikan dengan karakteristik masyarakat Surabaya yang modern dengan pendekatan karakteristik pemuda yaitu dinamis. Hal tersebut ditunjukkan dengan penggunaan bentuk-bentuk geometris, dengan komposisi asimetris.

Hasil desain interior UTD PMI Surabaya dengan Konsep Modern Youth secara keseluruhan membuat suasana interior UTD PMI Surabaya lebih dinamis, menyenangkan, dan memberikan suasana yang dapat mengurangi kesan klinis. Hal tersebut ditunjukkan dengan penerapan warna-warna analog, bentuk-bentuk geometris, dan penerapan desain furnitur yang fleksibel.
\end{abstract}

Kata Kunci: donor darah, desain interior, modern youth

\section{ABSTRACT}

Youth is the largest population in Indonesia and is promising to increase the availability of blood at the Indonesian Red Cross (PMI). PMI makes the program "Yang Muda Yang Berdonor" aims to encourage youths to make blood donation as a lifestyle. It needs a strategy to attract youths to come and donate their blood to the PMI Surabaya blood tranfusion unit. Improvisation on the conditions and facilities PMI Surabaya blood tranfusion unit through interior design is one strategy that can be done to support the improvement of blood donors among the youth. In determining the interior design concept PMI Surabaya blood tranfusion unit used methods of design through data collection phase (observation, interviews, surveys, literature) and design phases (exploration of ideas concepts, sketches, design and implementation). Through the process of design methods found that the concept is Modern Youth. The concept of Modern Youth is a concept adapted to the characteristics of Surabaya modern society with a dynamic approach to the characteristics of youths. The concept is shown by the use of geometric shapes, with asymmetrical composition.

The results of interior design PMI Surabaya blood tranfusion unit with the overall concept of Modern Youth make the interior atmosphere more dynamic, fun, and provide an atmosphere that can reduce the clinical impression. The concept is shown by the application of analogous colors, geometric shapes, and the implementation of flexible furniture designs.

Keywords : blood donation, interior design, modern youth 


\section{PENDAHULUAN}

Palang Merah Indonesia (PMI) sebagai organisasi kemanusiaan yang memiliki tugas khusus dari pemerintah yaitu melakukan pelayanan darah meliputi pengadaan, pengolahan, dan penyediaan darah terus berupaya untuk meningkatkan jumlah ketersediaan darah di Indonesia (PMI, 2009). Banyak upaya yang dilakukan untuk meningkatkan pendonor darah seperti penyediaan mobil donor yang digunakan untuk memudahkan pendonor tanpa harus datang ke Unit Transfusi Darah (UTD). Upaya lain yang dilakukan PMI adalah membuat sebuah program yaitu "Yang Muda Yang Berdonor". Program tersebut bertujuan untuk meningkatkan jumlah pendonor darah dikalangan usia dini, agar nantinya dapat menjadi gaya hidup yang akan berdampak pada jumlah ketersediaan darah di Indonesia

Sebagai salah satu Blood Donation Centre yang ada di Indonesia, UTD PMI Surabaya memiliki peran penting dalam mensukseskan program tersebut. Perlu strategi dalam meningkatkan jumlah pendonor darah usia muda. Strategi yang dapat dilakukan oleh PMI adalah dengan meningkatkan kualitas pelayanannya yang meliputi penanganan pendonor, dan fasilitas UTD PMI Surabaya (PMI, 2009).

Kondisi dan fasilitas UTD yang baik, dengan memperhatikan kenyamanan, keindahan, dan kemudahan mampu memberikan rasa nyaman pada pendonor darah baik secara fisik maupun psikologis. Hal tersebut dapat berdampak pada ketertarikan serta loyalitas pendonor untuk kembali lagi mendonorkan darahnya di UTD PMI Surabaya.

UTD PMI Surabaya dalam mendukung program PMI "Yang Muda Yang Berdonor" mengadakan event-event donor darah diberbagai tempat melalui kerjasama dengan instansiinstansi terkait seperti universitas atau SMA yang ada di Surabaya. Namun hal tersebut belum dapat menarik pendonor dari kalangan usia muda. Berdasarkan survey yang dilakukan penulis 77\% dari 30 responden yang merupakan pemuda Surabaya belum pernah mendonorkan darahnya, sementara 5 dari 7 orang responden yang menjawab pernah melakukan donor darah hanya melakukannya sekali.

Berdasarkan fakta tersebut dapat disimpulkan bahwa ketertarikan pemuda Surabaya untuk mendonorkan darahnya masih sangat rendah. Salah satu alasan tidak melakukan donor darah adalah sudah ada keinginian namun belum menyempatkan diri. Hal tersebut dapat terjadi karena tidak adanya faktor lain yang dapat menarik pemuda untuk mendonorkan darahnya khususnya pada UTD PMI Surabaya. Perlu adanya desain yang dapat memberikan suasana berbeda, dan menarik.

UTD PMI Surabaya berdiri sejak 1951 kemudian direlokasi di Jl. Embong Ploso 7-9 Surabaya pada tahun 1955. Kondisi fisik UTD PMI Surabaya dibangun dengan mengikuti standar-standar fungsional yang berdampak pada desain fisik bangunan. Hal ini tampak pada desain interior UTD yang masih bersifat sangat klinis. Perlu memberikan sentuhan desain yang lebih menarik melalui konsep desain interiornya. Hal ini perlu dilakukan sebagai upaya untuk meningkatkan ketertarikan pedonor darah usia muda. Melalui desain interior UTD yang menarik dapat memberikan pengalaman berdonor darah yang menyenangkan. Harapannya pendonor mau kembali untuk mendonorkan darahnya di UTD PMI Surabaya.

\section{A. Rumusan Masalah}

1. Bagaimana merumuskan konsep desain interior UTD PMI Surabaya yang sesuai dengan karakteristik anak muda?

2. Bagaimana membuat desain interior UTD PMI Surabaya yang mampu menarik seseorang untuk mendonorkan darahnya? 
3. Bagaimana mengurangi kesan klinis pada interior UTD PMI Surabaya?

\section{B. Tujuan dan Manfaat}

Tujuan dari desain interior UTD antara lain :

1. Redesain Interior UTD PMI Surabaya dengan konsep Modern Youth.

2. Menciptakan Interior UTD PMI Surabaya yang memberikan kenyamanan psikologis bagi pendonor.

Dengan desain ini diharapkan dapat memberikan kenyamanan pada pendonor darah, khususnya kalangan usia muda. Sehingga mampu mensukseskan program PMI agar anak muda dapat menjadikan donor darah sebagai gaya hidup, yang nantinya berpengaruh pada ketersediaan darah di Indonesia.

\section{METODOLOGI}

\section{A. Metode Pengumpulan Data}

Tahap pengumpulan data terbagi menjadi dua bagian, yaitu pengumpulan data primer yang didapat secara langsung (observasi partisipatif, kuisioner, dan wawancara) serta pengumpulan data sekunder yang didapat secara tidak langsung (studi pustaka).

\section{Observasi Partisipatif}

Observasi ini dilakukan peneliti dengan berpartisipasi langsung menjadi donor sukarela di UTD PMI Surabaya sebanyak enam kali. Tujuannya supaya dapat merasakan langsung pengaruh kondisi fisik interior UTD PMI Surabaya terhadap pendonor.

2. Kuisioner

Pengumpulan data kuisioner dilakukan untuk mendapatkan data faktual mengenai pemuda. Hal tersebut meliputi ketertarikan untuk donor darah, pengetahuan pemuda akan UTD PMI Surabaya, ketertarikan mengunjungi UTD untuk donor darah, pendapat tentang UTD PMI Surabaya, serta selera pemuda yang berkaitan dengan desain interior

3. Wawancara

Wawancara dilakukan pada pihak yang banyak mengetahui tentang prosedur dan standarisasi dari UTD. Narasumber dan rincian data yang ingin didapatkan:

a. Karyawan :

Mengetahui fungsi-fungsi ruangan yang ada, dan kendala-kendala yang berkaitan dengan sirkulasi ruangan pada setiap kegiatan yang ada pada UTD.

b. Petugas Medis:

Mengetahui proses penyadapan darah, standarisasi ruang AFTAP, dan kendala-kendala pada saat proses donor darah.

c. Pendonor :

Mengetahui pengaruh kondisi, dan fasilitas UTD terhadap pendonor baik secara fisik maupun psikologis.

4. Studi Pustaka

Didapatkan dengan menghimpun data yang relevan dengan topik yang dibahas pada objek desain. Pencarian dapat dihimpun melalui jurnal ilmiah, buku teks, majalah, artikel, internet dan lain-lain. 
Intan Hannah marysa, Nanik Rachmaniyah

Desain Interior Unit Transfusi Darah (UTD) PMI Surabaya dengan Konsep Modern Youth

\section{B. Metode Desain}

Metode desain ditunjukan pada bagan berikut :

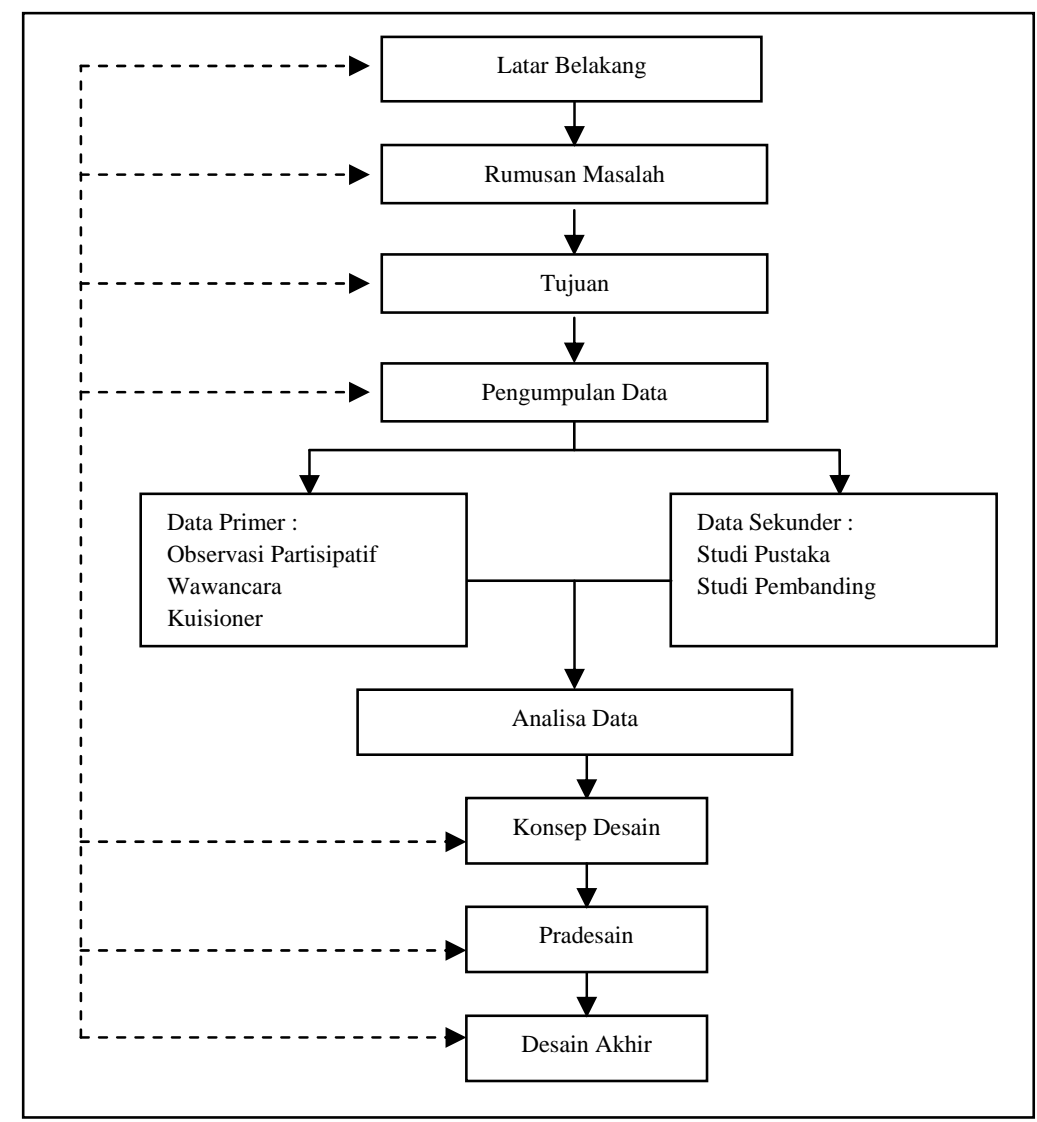

Gambar 1. Bagan Metode Desain

Sumber : Konstruksi Penulis (2016)

\section{KONSEP DESAIN}

\section{A. Objek Desain}

UTD PMI Surabaya terletak di Jl. Embong Ploso 7-9 Surabaya. UTD PMI Surabaya merupakan pusat pelayanan donor darah satu-satunya yang terletak di pusat Kota Surabaya.

\section{B. Konsep Desain}

Secara keseluruhan citra ruang yang ingin dicapai pada desain interior UTD PMI Surabaya adalah modern dengan sentuhan youth yang memberikan kesan dinamis pada ruang. Konsep ini diharapkan mampu mengalihkan perhatian pendonor dari rasa cemas, dan takut sebelum donor darah. Selain itu desain harus bersifat memotivasi, dan mengedukasi pendonor untuk menjadikan donor darah sebagai aktifitas rutin.

Dalam konsep desain interior UTD PMI Surabaya, modern dipilih sebagai implementasi gaya hidup masyarakat kota Surabaya yang merupakan masyarakat urban dan lekat dengan sesuatu yang bersifat modern. Sedangkan youth dipilih sebagai pendekatan pada anak muda agar lebih sesuai dengan selera mereka. 


\section{Aplikasi Konsep Desain}

\section{Konsep Ruangan}

Pada bangunan UTD, sirkulasi maupun zoning ruangan sudah mengikuti standart yang ditetapkan oleh WHO, sehingga tidak terdapat banyak perubahan pada sirkulasi, dan zoning. Perubahan hanya terdapat pada ruang donor karena perlu perluasan untuk menyesuaikan standart yang ditetapkan oleh WHO.

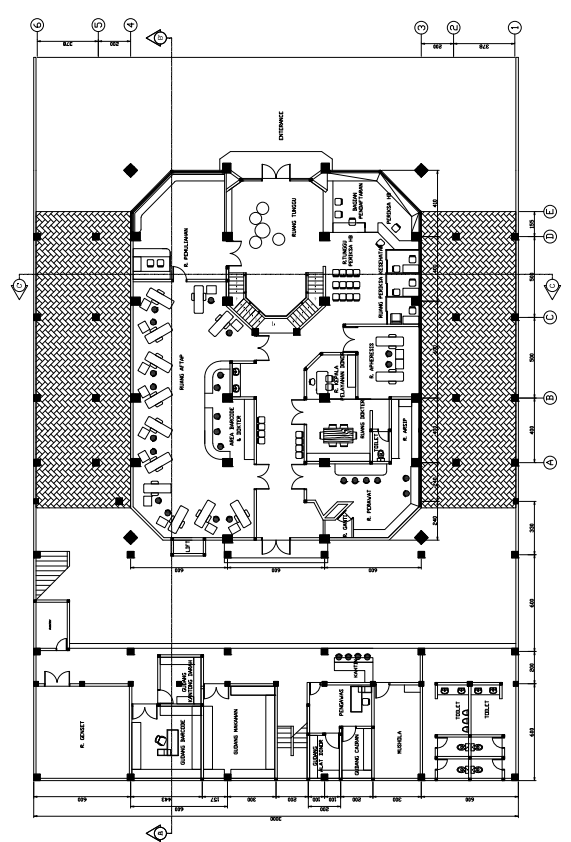

Gambar 2. Denah Terpilih

Sumber : Dokumentasi Penulis (2016)

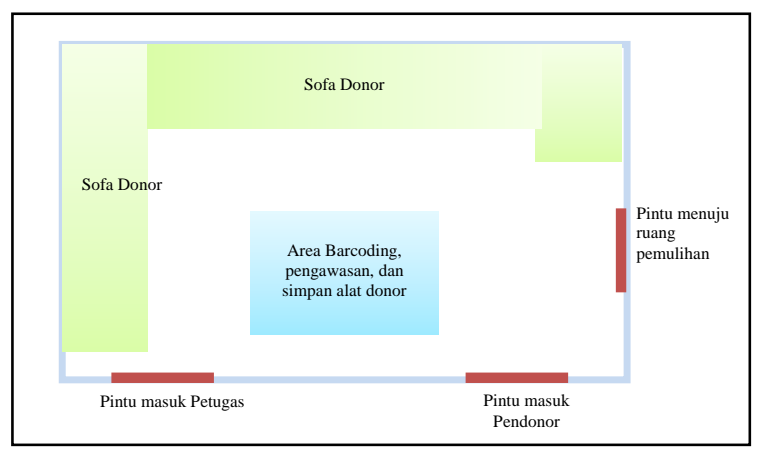

Gambar 3. Zoning pada Ruang Donor Sumber : Konstruksi Penulis (2016)

Zoning pada ruang donor (lihat gambar 3) yang demikian memberikan kemudahan dalam pengawasan kegiatan donor darah, selain itu sirkulasi bagi pengguna lebih leluasa.

\section{Konsep Bentuk}

Bentuk dominan untuk elemen estetis yang digunakan pada desain interior UTD PMI Surabaya adalah bentuk geometris segitiga yang diadaptasi dari 'heart rate' (lihat gambar 4) yang merupakan simbol kehidupan.

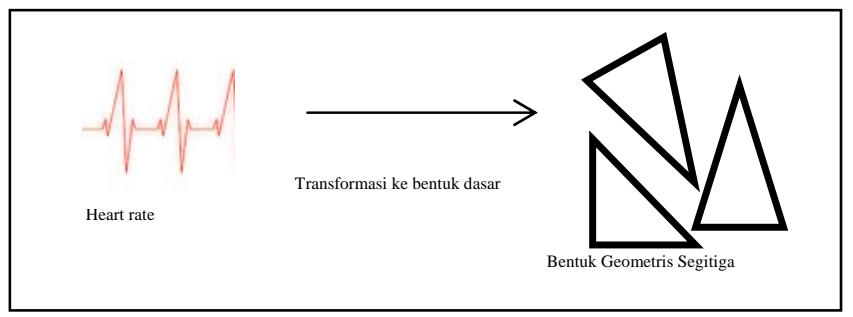

Gambar 4. Transformasi Bentuk Dasar Sumber : Konstruksi Penulis (2016)

Alternatif bentuk stool yang dipilih adalah alternatif II yang diadaptasi dari bentuk palang merah karena pada pengaplikasiannya sebagai stool memiliki kapasitas yang lebih banyak 
dari pada alternatif I, selain itu posisi duduk dan zoning yang jelas bagi pengguna. Pada ruang tunggu terdapat modular stool yang diadaptasi dari bentuk logo palang merah.

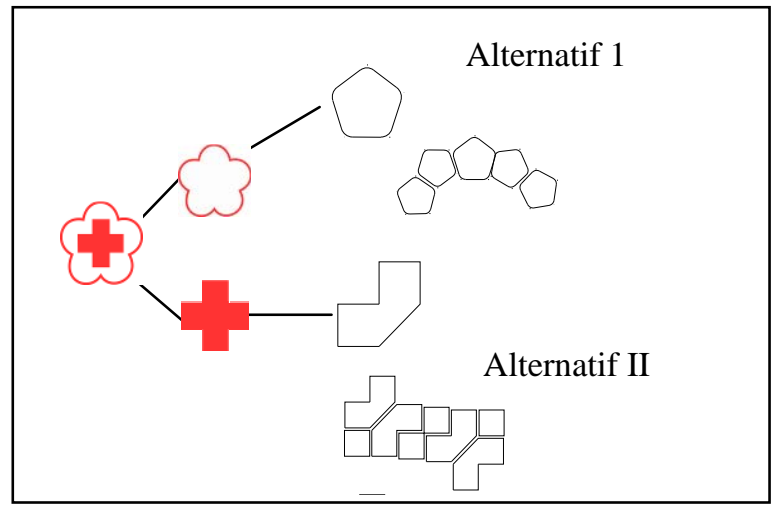

Gambar 5. Analogi Logo PMI

Sumber : Konstruksi Penulis (2016)

\section{Konsep Warna}

Warna yang akan diterapkan pada desain interior UTD PMI Surabaya adalah paduan dari beberapa warna komplementer, yang disatukan dengan warna dominan putih sebagai warna netral. Untuk mengurangi kesan klinis digunakan warna krem sebagai penyeimbang. Penggunaan warna-warna komplementer untuk menciptakan kesan desain youth. Berikut adalah warna-warna yang akan diterapkan pada desain interior UTD PMI Surabaya.

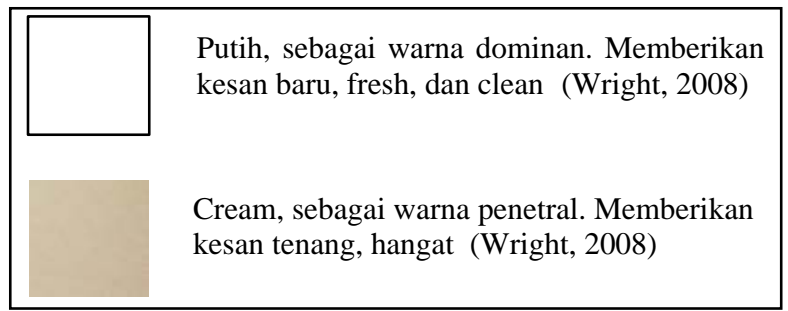

Gambar 6. Palet Warna Primar dan Sekunder

Kombinasi warna Youth yang diterapkan adalah perpaduan dari tiga warna. Perpaduan tiga warna diadaptasi dari komponen darah yang memiliki tiga unsur yaitu plasma, whole blood, dan sel darah putih (Azmi,A, 2013). Warna-warna yang dipilih adalah warna biru, magenta, dan limau. Warna biru diambil dari warna identitas PMI, sedangkan warna magenta dan limau dipilih karena memiliki efek pesikologis yang baik sesuai dengan karakter anak muda. Perpaduan warna ini diharapkan dapat mengurangi rasa cemas, gugup, dan kesan klinis pada interior UTD PMI Surabaya.

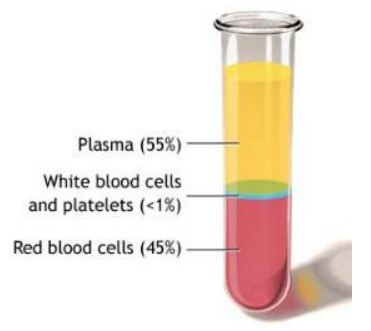

Gambar 7. Komponen Darah

Sumber : http://belajarterusbiologi.blogspot.com (2016) 


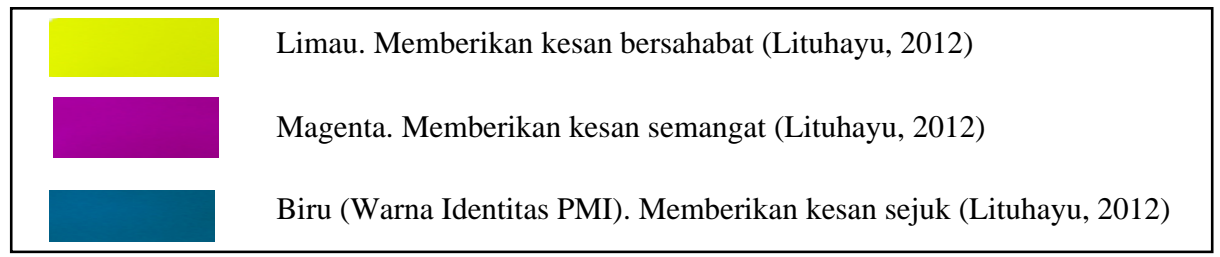

Gambar 8. Warna Komplementer

\section{DESAIN AKHIR}

\section{A. Ruang Tunggu}

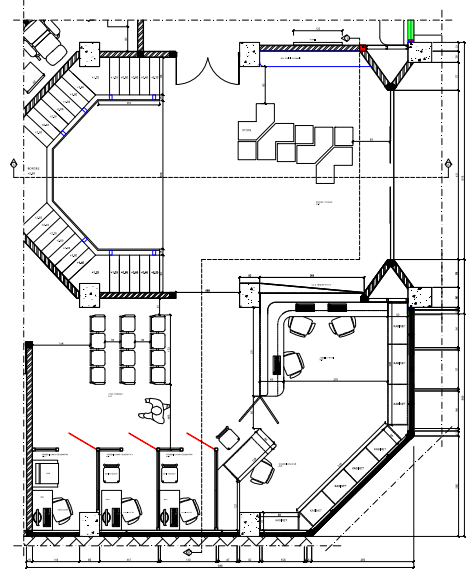

Gambar 9. Layout Ruang Tunggu Periksa Kesehatan Sumber : Dokumentasi Penulis (2016)

Ruang tunggu berfungsi sebagai tempat pendonor untuk menunggu antrian pendaftaran dan melakukan pengisian formulir. Ruang tunggu juga merupakan akses utama untuk masuk ke dalam gedung UTD PMI Surabaya. Dalam eksisting layout furnitur ruang tunggu sudah sesuai dengan sirkulasi sehingga layout furniturnya tidak mengalami banyak perubahan. Perubahan hanya dilakukan pada perletakan meja formulir pada satu area agar ruangan lebih efisien.

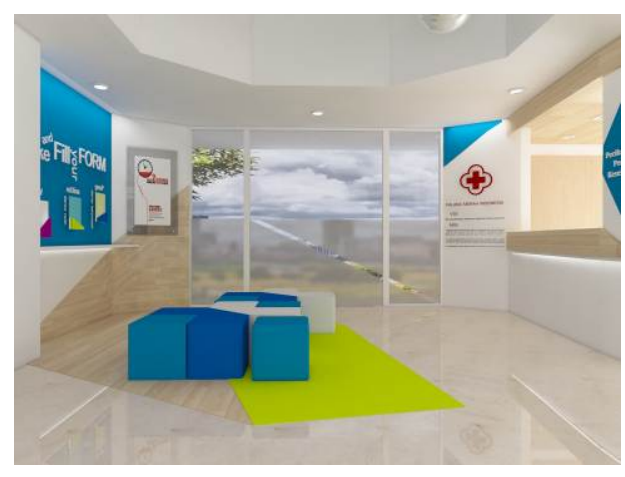

Gambar 10. Desain Ruang Tunggu Sumber : Dokumentasi Penulis (2016)

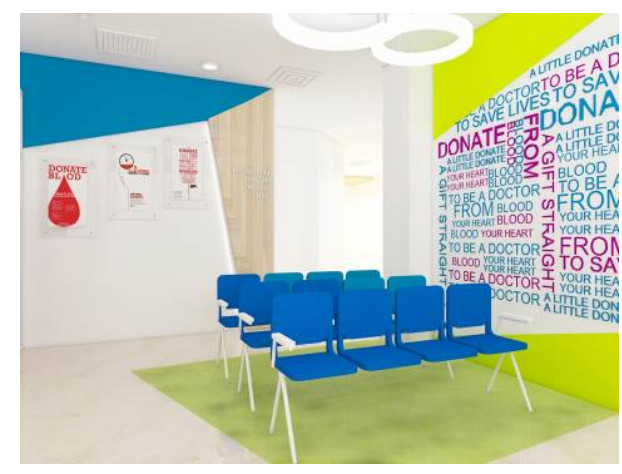

Gambar 11. Ruang Tunggu Periksa Kesehatan dan HB Sumber : Dokumentasi Penulis (2016)

Sebagai ruang utama gedung UTD PMI Surabaya, ruang tunggu dibuat netral, tidak terlalu banyak warna, namun tetap memiliki kesan youth. Konsep youth diaplikasikan pada warna dan bentuk elemen interiornya. Kesan youth juga dimunculkan melalui pengolahan 
dinding dan lantai dengan blocking area melalui bentuk asimetris, dan pengaplikasian warna yang playful. Sedangkan konsep modern diimplementasikan melalui efisiensi ruang, penggunaan furnitur yang fungsional serta penggunaan bentuk-bentuk geometris pada elemen-elemen interiornya.

Elemen estetis pada ruang tunggu dibuat fungsional. Elemen estetis juga berfungsi sebagai tempat formulir (pada area pengisian formulir), wayfinding, display poster, atau typography yang berisi kalimat motivasi.

\section{B. Ruang Donor}

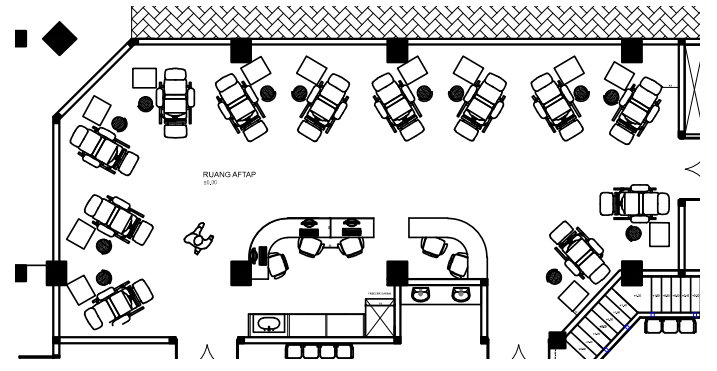

Gambar 12. Layout Ruang Donor

Sumber : Dokumentasi Penulis (2016)

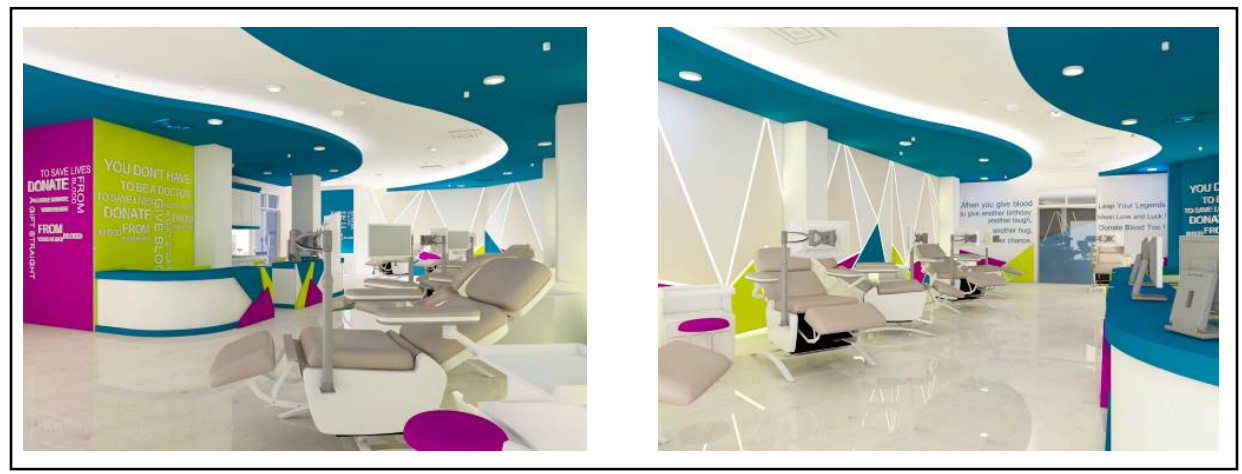

Gambar 13. Desain Interior Ruang Donor (view 1 dan 2) Sumber : Dokumentasi Penulis (2016)

Pada ruang donor dilakukan perluasan area sesuai dengan penambahan jumlah sofa donor dan jumlah meja kerja perawat. Hal tersebut dilakukan untuk pemenuhan standart oprasional yang ditetapkan WHO (WHO, 2010). Area pengawasan berada pada tengah ruangan untuk mempermudah pengawasan dan efisiensi ruangan. Pada ruang donor layout sofa donor dibuat berhadapan membentuk sudut $45^{\circ}$ agar tidak terlalu kaku dan terkesan dinamis. Untuk mengurangi kesan kaku juga dilakukan dengan membuat sudut-sudut melingkar pada furnitur meja area barcode dan area pengawasan.

Pada ruang donor, konsep modern youth diaplikasikan pada pengolahan dindimg, plafond, dan pemilihan warna pada ruangan. Elemen estetis yang digunakan pada ruang donor harus mempertimbangan kemudahan perawatan dan kebersihan. Elemen estetis yang diterapkan berupa pattern dan typhography. Pada sebagian dinding terdapat pattern dari komposisi bentuk segitiga dengan garis yang dipertegas oleh led strip. Pada sisi dinding lainnya menggunakan typography berupa slogan-slogan yang menginspirasi untuk terus berdonor. Pada plafon terdapat drop ceiling dengan bentuk melengkung dan terkesan dinamis mengikuti arah sirkulasi ruang. 


\section{Ruang Pemulihan}

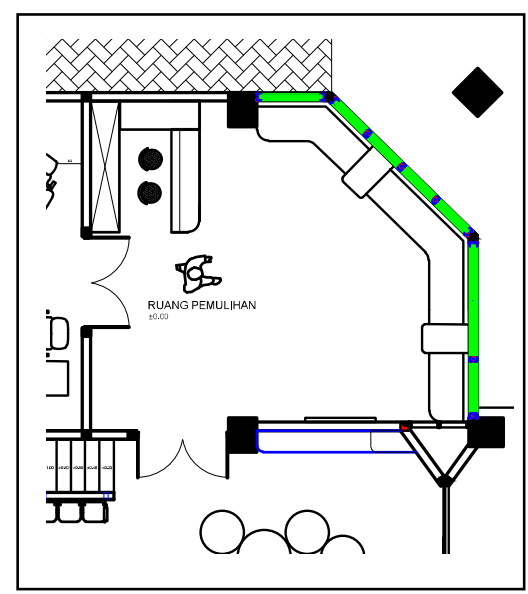

Gambar 14. Layout Ruang Pemulihan Sumber : Dokumentasi Penulis (2016)

Ruang pemulihan pada eksisiting kurang berfungsi secara optimal. Sebagian besar pendonor cenderung langsung pulang setelah donor. Untuk itu ruang pemulihan didesain dengan konsep lounge supaya pendonor bisa lebih santai. Untuk effisiensi ruang, ruang pemulihan menggunakan built in sofa yang mengikuti bentuk ruang.

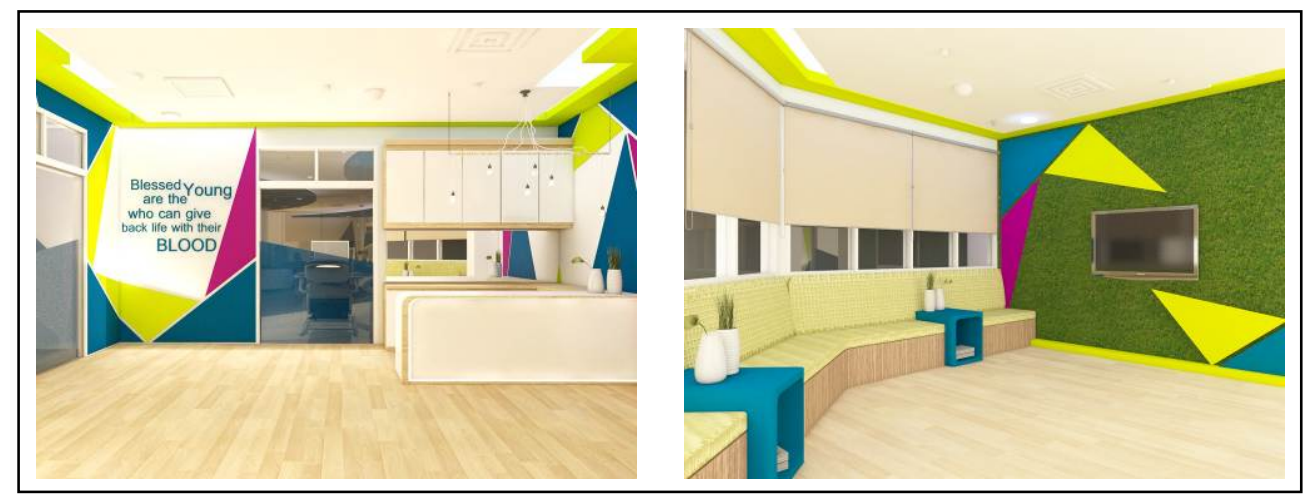

Gambar 15. Desain Ruang Pemulihan

Sumber : Dokumentasi Penulis (2016)

Ruang pemulihan memiliki konsep khusus yaitu lounge atau area santai. Di dalam ruang ini pendonor diharapkan bisa merasa lebih nyaman, santai, dan rileks. Konsep relax dan cozy pada ruang pemulihan diimplementasikan dengan pemilihan furnitur berbentuk sofa yang dilengkapi beberapa coffe table dan penggunaan rumput sintetis pada dinding area konter makanan. Desain pada ruang pemulihan mengadaptasi desain-desain pada café yang merupakan tempat anak-anak muda menghabiskan waktu untuk bersosialisasi bersama temantemannya. Suasana café dimunculkan dengan lampu gantung bergaya industrial.

\section{KESIMPULAN}

Dari pembahasan Desain Interior UTD PMI Surabaya dengan Konsep Modern Youth, dapat disimpulkan beberapa hal, yaitu :

1. Konsep Modern Youth merupakan konsep desain yang tepat untuk diterapkan pada desain interior UTD PMI Surabaya yang ingin meningkatkan pendonor darah usia muda. 
Intan Hannah marysa, Nanik Rachmaniyah

Desain Interior Unit Transfusi Darah (UTD) PMI Surabaya dengan Konsep Modern Youth

Konsep Modern Youth diharapkan dapat menghilangkan kesan klinis pada desain interior UTD. Ini penting untuk mengubah merubah persepsi masyarakat terhadap kegiatan donor darah dari aktivitas yang menakutkan menjadi aktivitas yang keren dan menyenangkan.

2. Konsep Modern Youth merupakan konsep yang disesuaikan dengan karakteristik masyarakat Surabaya yang modern dengan pendekatan karakteristik pemuda yaitu dinamis. Hal tersebut ditunjukkan dengan penggunaan bentuk-bentuk geometris dan komposisi asimetris. Bentuk geometris yang dipilih adalah bentuk segitiga yang dinamis dan merupakan analogi dari heart rate sebagai simbol kehidupan. Warna yang diterapkan adalah warna yang memberikan kesan playful dan bersahabat, diadaptasi dari kombinasi tiga komponen darah dengan pilihan warna limau, magenta dan biru.

3. Hasil desain secara keseluruhan membuat suasana interior UTD PMI Surabaya lebih dinamis, dan menyenangkan. Hal tersebut ditunjukkan dengan penerapan warna-warna komplementer dan bentuk-bentuk geometris pada elemen interior. Hasil desain dengan penerapan konsep modern youth dapat mengurangi kesan klinis interior UTD PMI Surabaya.

\section{SARAN}

Di Indonesia desain pada UTD masih menyerupai rumah pengobatan atau Rumah Sakit jaman dahulu. Pendonor perlu mendapatkan fasilitas dan layanan yang lebih baik karena pendonor bukanlah seorang pasien. Aktivitas donor darah yang mulai bergeser menjadi sebuah gaya hidup sebaiknya difasilitasi lebih baik lagi. Hal-hal selain pelayanan dan bersifat non teknis seperti nuansa interior pada bangunan juga perlu diperhatikan supaya bisa memberikan pengalaman yang menyenangkan bagi pendonor.

\section{DAFTAR PUSTAKA}

Azmi, A. (2013). Belajar Sepanjang Hayat. Retrivied from : http://arijal-ridzarti.blogspot.co.id/2013/05/fisiologi-darah.html

BPS. (2013). Proyeksi Penduduk Indonesia 2010-2035. Jakarta: BPS.

Kementrian Kesehatan RI. (2014). Situasi Donor Darah di Indonesia.

Lituhayu, C. (2012). Pengaruh Warna Terhadap Psikologi Pengguna dalam Perancangan Fasilitas Bedah Plastik Estetik. ITB Undergraduate Journal of Visual Art and Design, Vol.1No.12012. Retrivied from : http://jurnal-s1.fsrd.itb.ac.id/index.php/interior/ article/view/25

Palang Merah Indonesia. (2009). Kenali PMI. Jakarta, Indonesia.

Palang Merah Indonesia. (2006). Graphic Standart Manual. Jakarta, Indonesia.

Sari, Sriti Mayang (2004). Peran Warna Pada Interior Rumah Sakit Berwawasan 'Healing Environment' Terhadap Proses Penyembuhan Pasien. Jurnal Dimensi Interior Vol.1 No.2 Desember 2003, h. 141-156.

WHO. (2010). Design Guidelines for Blood Centres. WHO Press

Wright, A. (2008). Psychological Properties Of Colours. Retrivied from : Colour Affects: http://www.colour-affects.co.uk/the-colour-affects-system 